\title{
Supporting Educational Activities through Dynamic Web Interfaces
}

\author{
Maria da Graça Pimentel (mgp@icmc.sc.usp.br) \\ Instituto de Ciências Matemáticas e de Computação, Universidade de São Paulo \\ Caixa Postal 668, São Carlos, SP. 13560-0960. Brazil. \\ Tel +55 (16) 273-9657. Fax +55 (16) 273-9751. \\ Yoshihide Ishiguro (ishiguro@hml.cl.nec.co.jp) \\ Human Media Research Laboratories, NEC Corporation \\ 8916-47, Takayama-cho. Ikoma, Nara 630-0101. Japan. \\ Tel. +81 (743) 72-3864. Fax +81 (743) 72-3549. \\ Bolot Kerimbaev (bolot@cc.gatech.edu) \\ Gregory D. Abowd (abowd@ cc.gatech.edu) \\ Mark Guzdial (guzdial@cc.gatech.edu) \\ College of Computing \& GVU Center, Georgia Tech \\ 801 Atlantic Drive, Atlanta, GA 30332-0280, USA. \\ Tel. +1(404) 894-7512. Fax +1(404) 894-2970.
}

\begin{abstract}
The Web is used for many purposes in education, such as the publication of course management information, centralized distribution of course material, and supporting on-line discussions between instructors and students or among the students themselves. Leveraging off the Web for educational activities both inside and outside the classroom produces a dynamic educational repository. In this paper, we present work that explicitly attempts to connect in-class activity, in the form of multimedia, Web-accessible captured lectures, with collaborative discussion spaces. Flexible and dynamic interfaces for the captured lectures and the discussion spaces are presented, as well as specialized interfaces that connect the two. We discuss our experience in a recent course taught using this integrated and dynamic educational repository and explain how our experience has lead to some solutions for visualizing the changes that occur over this rich space.
\end{abstract}


Keywords: educational application, automated capture and access, collaborative discussion, hypertext, multimedia, ubiquitous computing

\section{INTRODUCTION}

Few would question the impact that the World Wide Web has had in transforming our information society. We are only beginning to understand our basic information consuming tasks within this ubiquitous information infrastructure, as those tasks co-evolve with the rapid pace of change in the infrastructure and content base itself. In this paper, we want to explore the current and future impact of Web content change in the particular context of university education.

Within most universities, the Web serves as a repository for educational materials. Skeptics might point out that the Web initially provided only a fairly static information distribution channel and served simply to off-load the task of photocopying from the institution to the individual. This observation misses out on some of the more active uses of the Web that are currently being explored. Many tools have been created in order to support the tasks of publishing material generated outside of the classroom to the Web. However, there is less support to provide Web access to material generated within the classroom and even less to integrate that in-class experience with the rest of the educational material provided outside of the

classroom. Addressing that open area, and discussing solutions and challenges to providing effective interfaces to what quickly becomes a large and dynamic information space, is the purpose of this paper. 
For the past five years, we have worked on a project, Classroom $2000,{ }^{2}$ whose goals are to provide automated ways to transform the rich content of a traditional university lecture into browsable, searchable and extensible digital media that serves both short- and long-term educational goals (Abowd et al., 1996; Abowd et al., 1998; Brotherton, Abowd \& Bhalodia, 1998; Abowd, 1999; Truong \& Abowd, 1999). Our goal in this paper is to demonstrate how captured classroom lectures can serve as one part of a rich and dynamic educational repository. We will demonstrate by example how effective interfaces to captured lectures can help a user (in this case, a student or an instructor) handle the inherent dynamics of an ever-growing Web repository.

\section{Overview}

We will begin by describing our own framework for understanding the source and relationships for how educational material evolves. We will then describe how we have used ubiquitous computing technology to instrument a classroom environment and provide extensible and Webaccessible interfaces that capture much of the details of classroom lectures and deal with providing a coherent view of an ever-growing repository of information. We next discuss how the Web is used to facilitate collaborative discussions in an educational context and how facilitate the anchoring of discussions and activities outside the lecture to the captured lectures themselves. We have created an instance of an educational repository that links in-class and outside-class activity, and we will report on that experience and the lessons learned for presenting interfaces that provide useful indicators of change in the underlying information.

\footnotetext{
${ }^{2}$ In this paper, we will refer to the project by its original name, Classroom 2000. On January 1, 2000, the project was renamed eClass.
} 


\section{A Framework fOr Understanding the EVOlution of EduCational Material}

A typical classroom-based course usually runs for a certain period, or term, during which time live lectures are presented on a regular basis, such as twice a week. Participating in such a course is a highly demanding activity both for the students and the instructor. From the instructors' perspective, many tasks have to be performed - preparing lectures, assignments and examinations, reviewing and assessing student work. Students are also engaged in many tasks - reading, participating in class discussions, completing assigned personal or group work, studying and taking exams. All of these tasks generate material that is in some way relevant to the educational goals of the course. Some example artifacts for a given course might be any slides prepared and presented by the instructors, and notes written on a public whiteboard during lecture, and essays or assignments prepared by students outside of the lecture. The body of material associated with a single course grows during the timeframe of the course itself. Activities performed by students and instructors, at any time during a course, usually involve knowledge acquired in more than one lecture, or even from previous courses. This scenario illustrates the following features associated to the body of material generated in the course:

- Active growth: The amount of material expands after each lecture during the course, as a result of the contribution of all participants in the course.

- Intrinsic referencing: The users, students and instructors, are constantly referring to any portions of the material contained in the course.

It is a challenge for instructors and students to keep up with the amount of information produced in a course. The diversity of activities performed by these users makes it difficult to process the information and store it for later retrieval. However, computers, with the help of ubiquitous 
infrastructure like the Internet and the Web, are tools that should be exploited for helping the users with the tasks of managing, storing and retrieving much of the ever-changing information produced in an educational setting.

The use of the Web in typical classroom-based courses has taken many forms, varying from the publication of course management information to supporting the delivery of material by instructors and students. For instance, management information includes course description or assessment rules; instructors' material includes list of readings and prepared lectures; students' material includes handing in essays and contributing articles to newsgroups. Most tools that provide such support are meant to be used outside the classroom, offering services that refer to material produced before or after the classroom experience, such as WebCT (Goldberg \& Salari, 1997) and DocTools (Pimentel, Santos \& Fortes, 1998). Since these tools are usually associated to an instance of a course, they are able to offer an interface that reflects the growth of the body of material they support. However, because they are not directed toward including information generated within the classroom during lecture, the rich multimedia interaction that occurs during each lecture is left out of the Web repository associated to the course.

In many courses the primary learning context is the classroom. Whether the classroom is used for lecture, discussion, or even face-to-face collaborative activity, the experiences in the classroom are often the central activities that we want students to reflect upon and learn from. Therefore, in order to give a more comprehensive support for classroom-based courses, the tasks performed inside the classroom have to be supported. Moreover, discussions occurring outside the classroom also have to be integrated to the body of information for the course, particularly those having contents discussed in the classroom in deeper or broader levels. 


\section{A spiral framework of dynamic course material generation}

The body of information produced in a typical classroom-based course corresponds to activities held both inside and outside the classroom, corresponding to before, during and after the live lecture. Before the lecture, the instructor prepares the lecture content and students prepare by going over assigned readings. During the lecture, the instructor's activities include delivering the prepared presentation and answering to students' questions, while the students' tasks include participating in discussion and taking notes. After the class, student's work on homework and discuss the class contents with the instructor and other students, while the instructor interacts with students on clarifying class content and makes any adjustments in the course plan.

Such a perspective indicates that the body of information for a course is generated by many diverse activities generated by different users at different times and places. Using lecture dates as a landmark in the course, the various activities are categorized as to whether they occur before, during or after a given lecture. As a course evolves, we consider the spiral of activities (shown in Figure 1) that lead to the overall educational repository being created. Each traversal of the spiral represents the activities associated with a single lecture. As each new lecture passes, the body of information continues to grow. In addition, since most classes build up knowledge based on previously presented material, the repository of information for the course becomes more and more interrelated, many new concepts being built upon previously learned material.

This simple spiral framework illustrates two important features of the body of information being generated, active growth and intrinsic referencing:

- The active growth is indicated by: (a) the expansion of the spiral that, at each turn, covers a larger space reflecting the amount of information produced, and (b) by the concentric 
organization of each turn of the spiral, reflecting that the information produced in each turn

\section{Before lecture}

- Instructor assigns readings

- Instructor prepares contents

- Instructor prepares slides

- Instructor prepares quizzes

- Instructor defines homework

- Students work on readings

- Instructor clarify contents to students

During lecture

- Instructor delivers presentation

- Students asks questions

- Group holds discussion

- Instructor presents quizzes

- Students deliver homework

- Instructor clarify contents to students

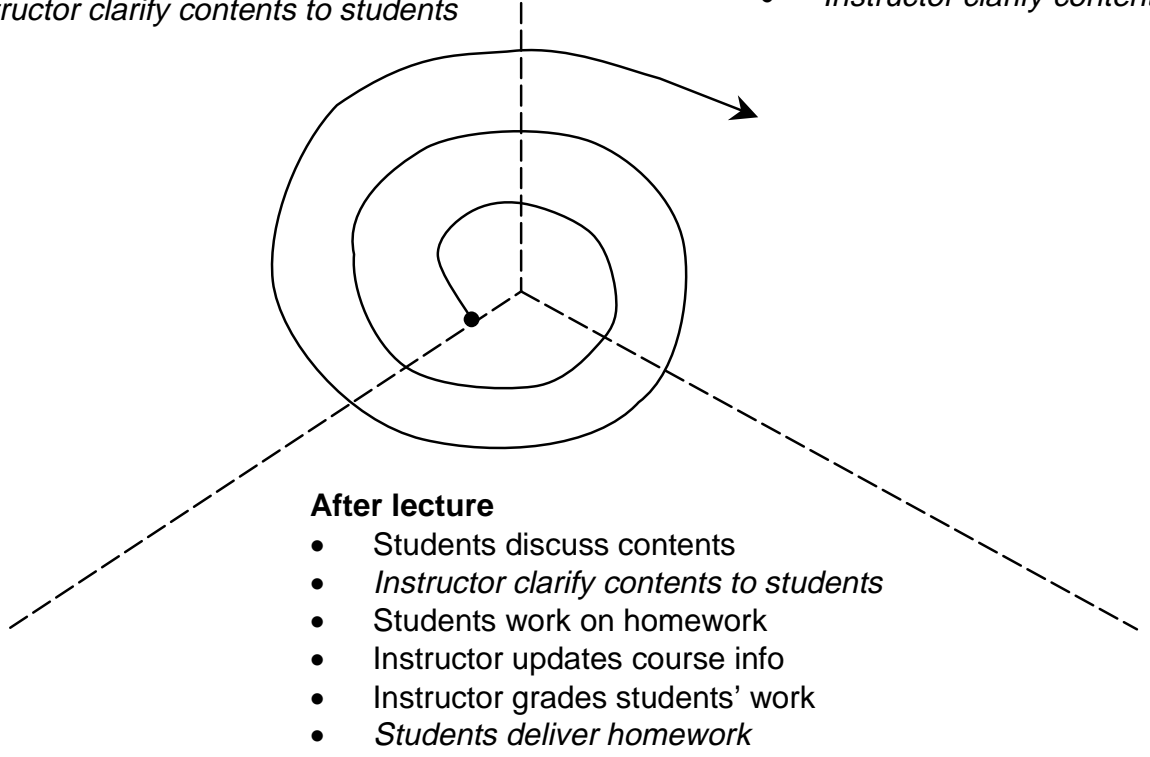

builds up over the previous existing information.

- The intrinsic referencing is illustrated by the fact that the spiral traverses the three phases while expanding, therefore allowing the users reference to material at any point in previous time, independently of the phase in which it was produced.

Figure 1: Spiral model of dynamic course material generation. Italicized activities represent activities supported in our prototype system.

In order to investigate the issues related to supporting activities as covered by the spiral model, we have built an environment that supports some activities in all three stages. Our primary approach was to exploit the Web as the delivery platform for both presenting and supporting the generation of the body of the information for the course. Our target was to make the Web 
repository for a course to reflect the dynamic body of information that is generated and updated as the teachers and students actively work during the evolution of a course. We will describe our system in its two main parts. We will first describe how the classroom experience is captured in an electronic form and made available in a multimedia format for later review. A growing repository of captured lectures from a course alone presents interesting challenges when providing effective interfaces. We will discuss some of our solutions that have been in place for the past three years and some of our more recent advancements. We will then discuss how separate research has developed Web-based collaborative tools for educational uses and show how we have built an educational repository for a single course that is a combination of captured lectures and collaborative work.

\section{BRINGING THE CLASSROOM EXPERIENCE TO THE REPOSITORY}

The classroom itself can be seen as a rich multimedia environment where dense audio-visual information is combined with miscellaneous annotating activities that support the teaching and learning experience. To capture this rich experience for later reflection, typical students develop note-taking skills. It is becoming increasingly difficult for students to keep up with the barrage of information instructors are enabled to present, especially when the student is equipped with only paper and pen. We do not want to encourage students to hone stenographer-like skills in lieu of understanding and synthesizing the relevance of the lecture and putting it in their own words. Furthermore, the students' personal notes, in isolation of the rest of the lecture, are still hard to use as an anchor for class-wide discussion of lecture activities.

In an attempt to ease both the task of capturing the classroom activities and the burden of creating Web-based digital media, we instrumented a space that turns the traditional classroom into a multimedia authoring system. Our system uses some ubiquitous computing technology — 
electronic whiteboards, large projected displays, networked computers, and streaming digital audio/video - in order to create a room that automatically captures much of the rich detail of a lecture experience. We leverage off the ubiquity of the Web to provide universally accessible interfaces for both students and teachers to review the lecture.

We have gained extensive experience using this capture system alone as a service to students and teachers and Abowd (1999) has published an account of the benefits of this capture technology. One of the main results is that the student is allowed to take on a different, more enriching role in the classroom and, at the same time, the instructor is provided with a tool to generate Web-based material without significant added effort. Figure 2 presents the actual classroom with the capturing functionality (left), and a sample interface for reviewing the material on the Web (right).
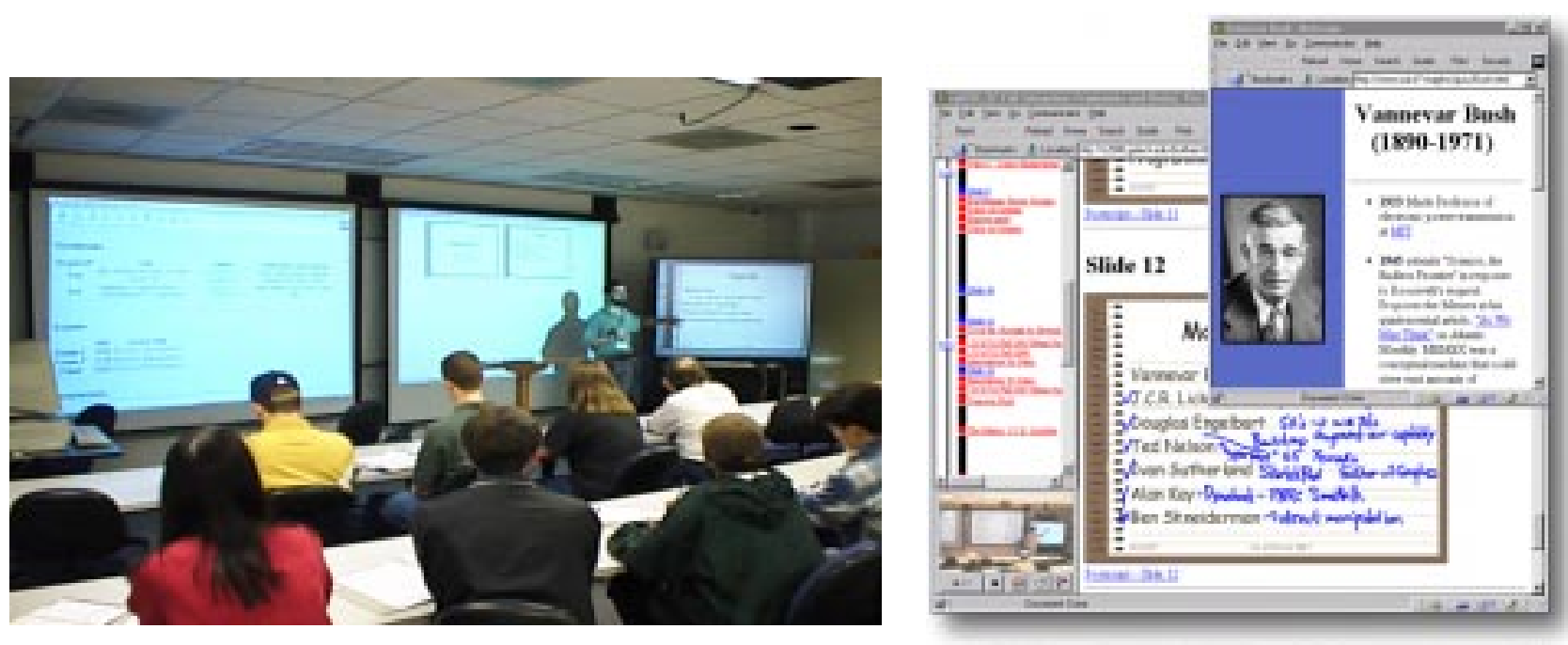

Figure 2: (left) The Classroom 2000 environment with the capturing whiteboard, projectors, cameras and microphones. (right) Web browsers are used for reviewing the captured notes that link presented material from the electronic whiteboard and Web pages visited in class with streaming digital audio/video recorded during class.

There is little value in providing Web access to the contents for the captured lectures if no services are provided to help the users in retrieving some relevant information. We will present 
some of the services provided for the ever-growing collection of captured lectures for a single course next.

\section{Presenting the contents of captured lectures}

Access to the captured lecture information is most naturally done in the after-lecture and beforelecture phases: for instance, students may want to review some points discussed in a lecture when preparing their homework, and instructors may want to review a set of lectures while preparing a future one.

The collection of captured lectures for a single course is presented as a syllabus organized by lecture dates. Figures 3 and 4 depict two different forms of syllabi that present previously captured lectures to the viewer. The repository of captured lectures is actually a database with a standard SQL interface and all of the Web pages you will see in this section are generated by server-side scripting that generates plain HTML dynamically. Each syllabus allows the student

to access a given lecture with either audio or video augmentation and in a way that can

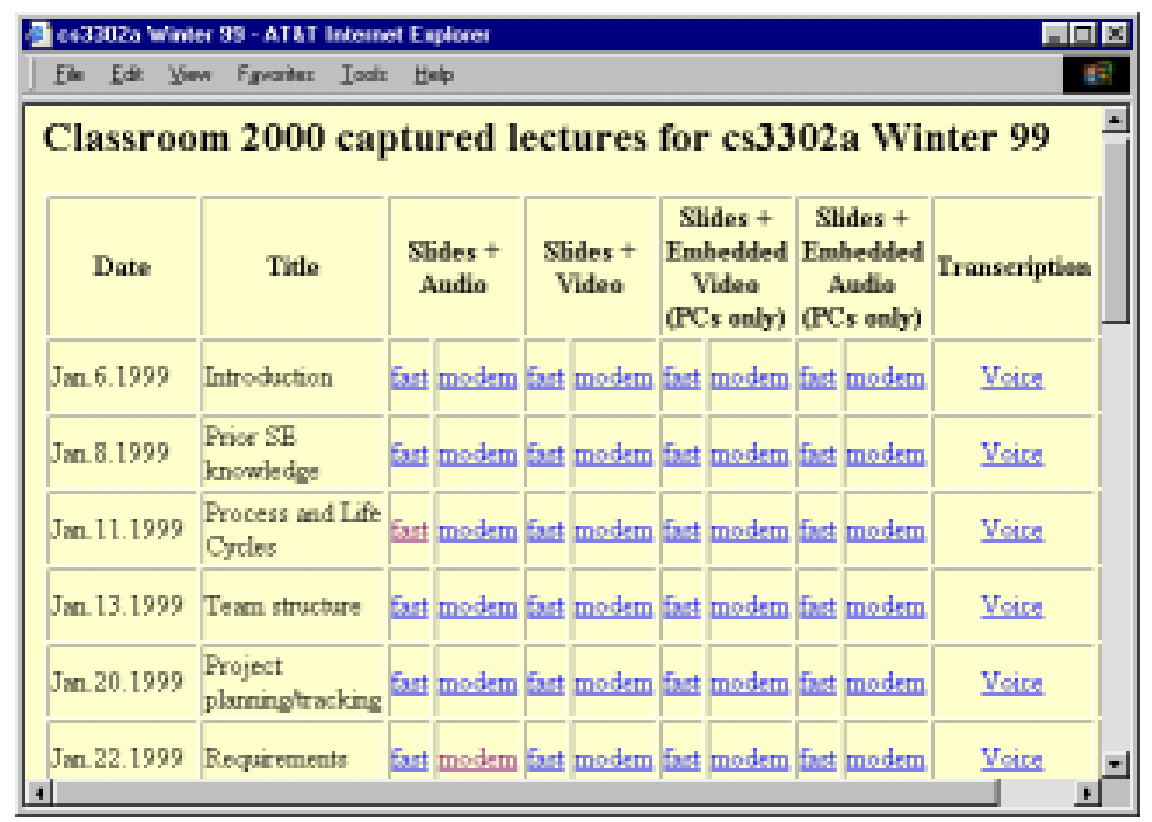

Figure 3: Automatically-generated syllabus of captured lectures 
accommodate either a fast or slow network connection. In Figure 3, the audio/video and fast/slow options are provided as explicit links the user can select. In Figure 4, a separate set of radio buttons before the syllabus allows the user to select audio/video or fast/slow that then applies to the selection of the captured lecture for any date. The Web page shown in Figure 4 also integrates a form that allows searching over the repository. The use of this feature is discussed later in this section.

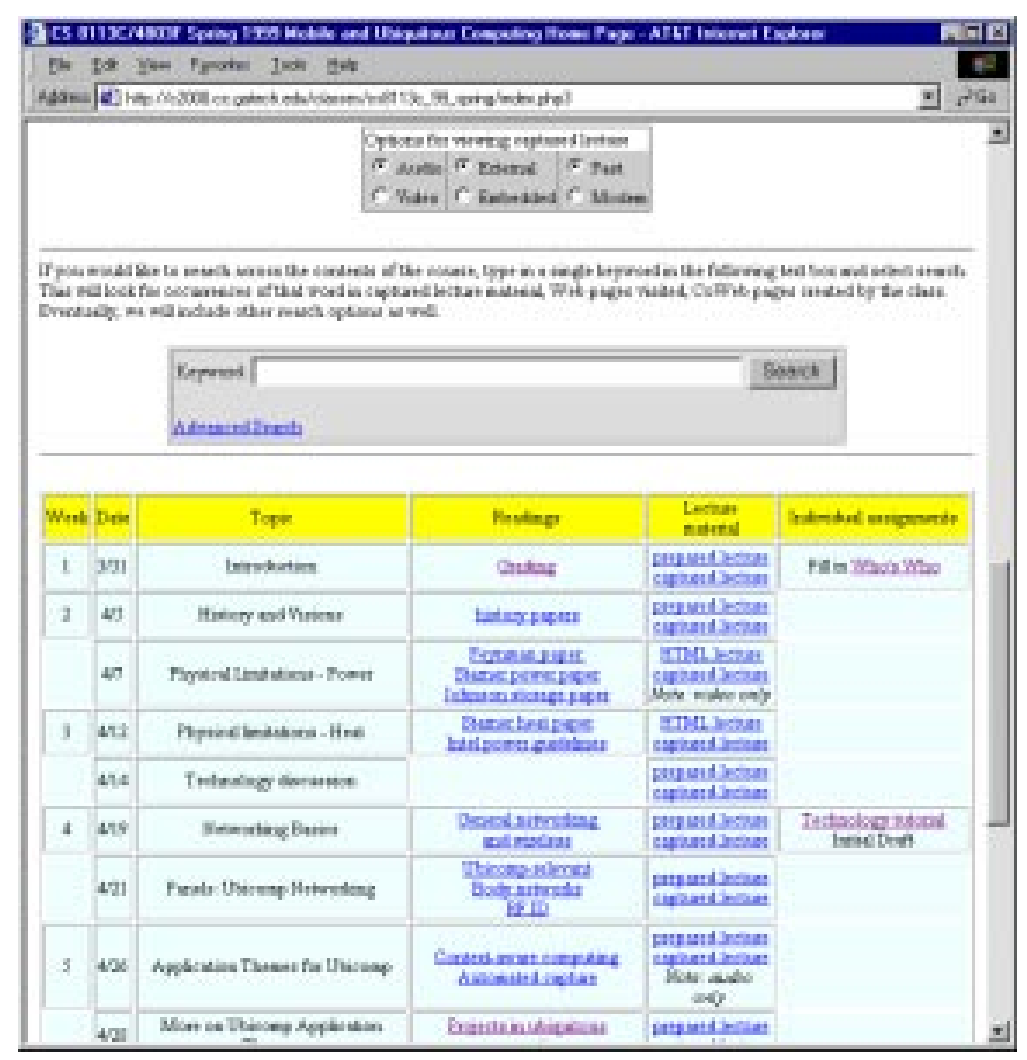

Figure 4: Alternative syllabus interface

The lecture itself is divided into discrete slides, that typically represent one screen's worth of information generated on the electronic whiteboard (shown on the right of the classroom photo in Figure 2). Instructors can use prepared presentations or simply write on a blank whiteboard in class. Figure 5 shows notes from a class in which the instructor wrote on a blank whiteboard. Figure 6 shows an example lecture in which a prepared presentation was shown. In each case, a 
timeline on the left depicts relevant activity as it happened in class. That relevant activity indicates either a new slide being created on the whiteboard or a Web page being visited on a

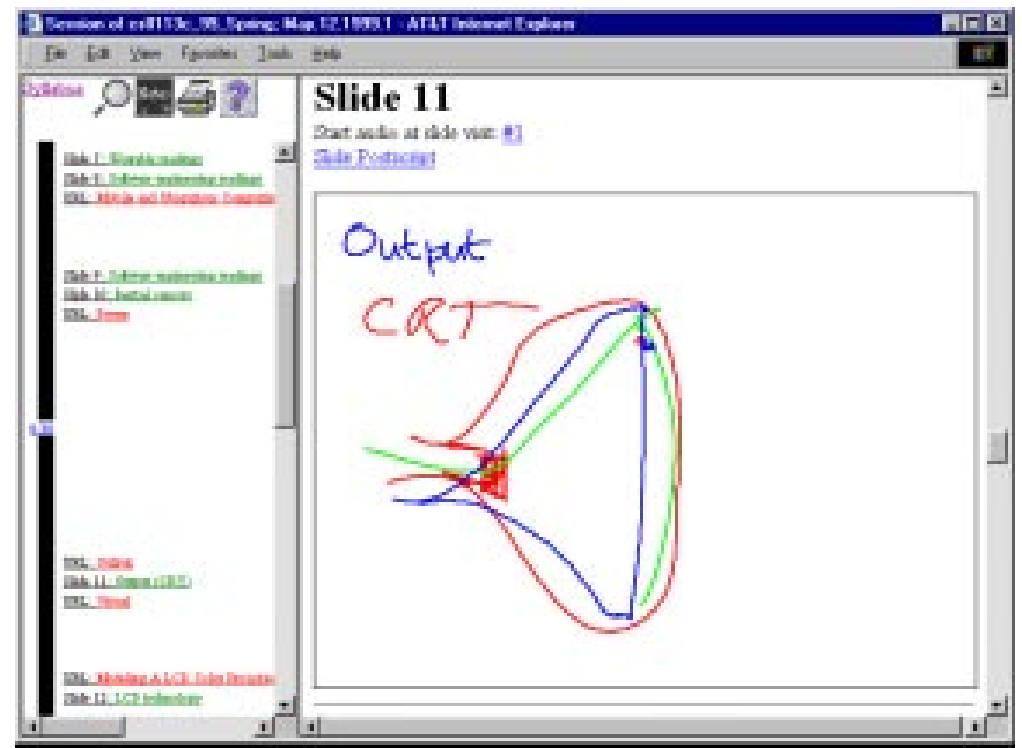

Figure 5: Typical presentation interface for one-slide-a-time (blank whiteboard)

separate display in class. The slide and Web page are marked with their title, when that information is known. The ink on the slides is also sensitive, meaning that clicking on the instructor's handwriting will launch an audio or video player at the point in the lecture when the instructor wrote that annotation.

Providing access to the right portion of audio or video when reviewing the contents of a lecture may be a difficult task. The presentation interface supports some resources for helping the user in locating a particular piece of audio our video. The timeline is used as an index to the corresponding offset within the media stream. The instants in which the instructor switched between slides are also recorded, and are indicated in the interface using the number of visits that a slide had above the slide itself; the number can be used to index into the stream of media. Finally, all the markings done by the instructor (handwriting and drawings) are presented as 


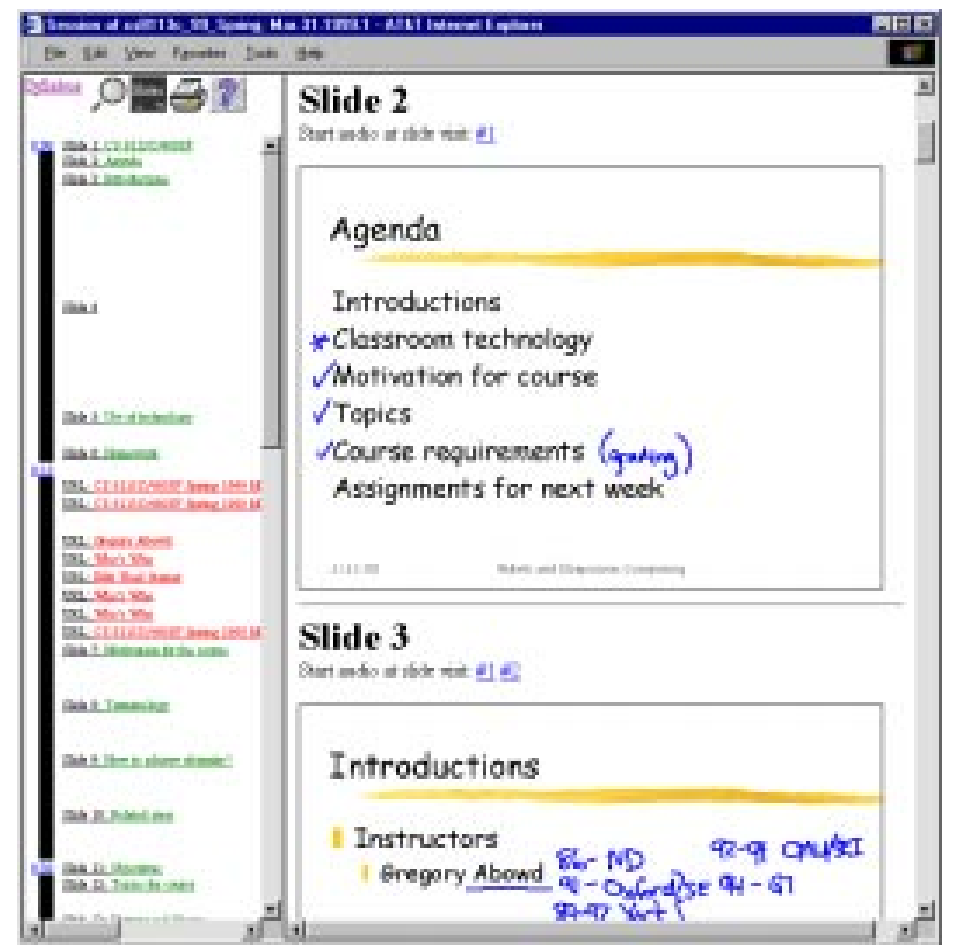

Figure 6: Presentation interface for all slides at once (using prepared slides)

indexing anchors to the stream. This integration between the handwritten ink and the audio or video is itself an interesting challenge, and has been addressed elsewhere (Brotherton, Abowd \& Bhalodia, 1998). This last feature is particularly important, since an instructor can spend a long time presenting a single slide, and the timeline and slide transition landmarks do not offer adequate granularity for indexing in that timeframe. Moreover, the marking itself is likely to provide a good index for the audio and video captured when it was produced.

\section{Augmenting the content of material captured during lecture}

In addition to capturing classroom content for random-access replay, we wanted to support other access tasks that would rely on having knowledge of the content of a lecture. We built tools to automatically extract the prepared content of a presentation and place it in our capture repository. In a number of couses, we also experimented with the use of speaker-dependent continuous speech recognition software to generate transcripts that were then automatically timestamped to 
synchronize with the lecture. Some information streams, however, are very difficult to extract through automatic means and may not even occur during the live lecture. We provide some simple editing services to allow additional information to be associated with a lecture after it has been captured. The editing interface allows the instructor to augment the information relative to a captured lecture. In Figure 7 we show the editing interface that allows the instructor to provide additional information about a lecture, such as slide titles, translation of handwriting (handwriting recognizers do not perform well when handwritten text is combined with gestures and drawings) and additional comments on the lecture discussion.

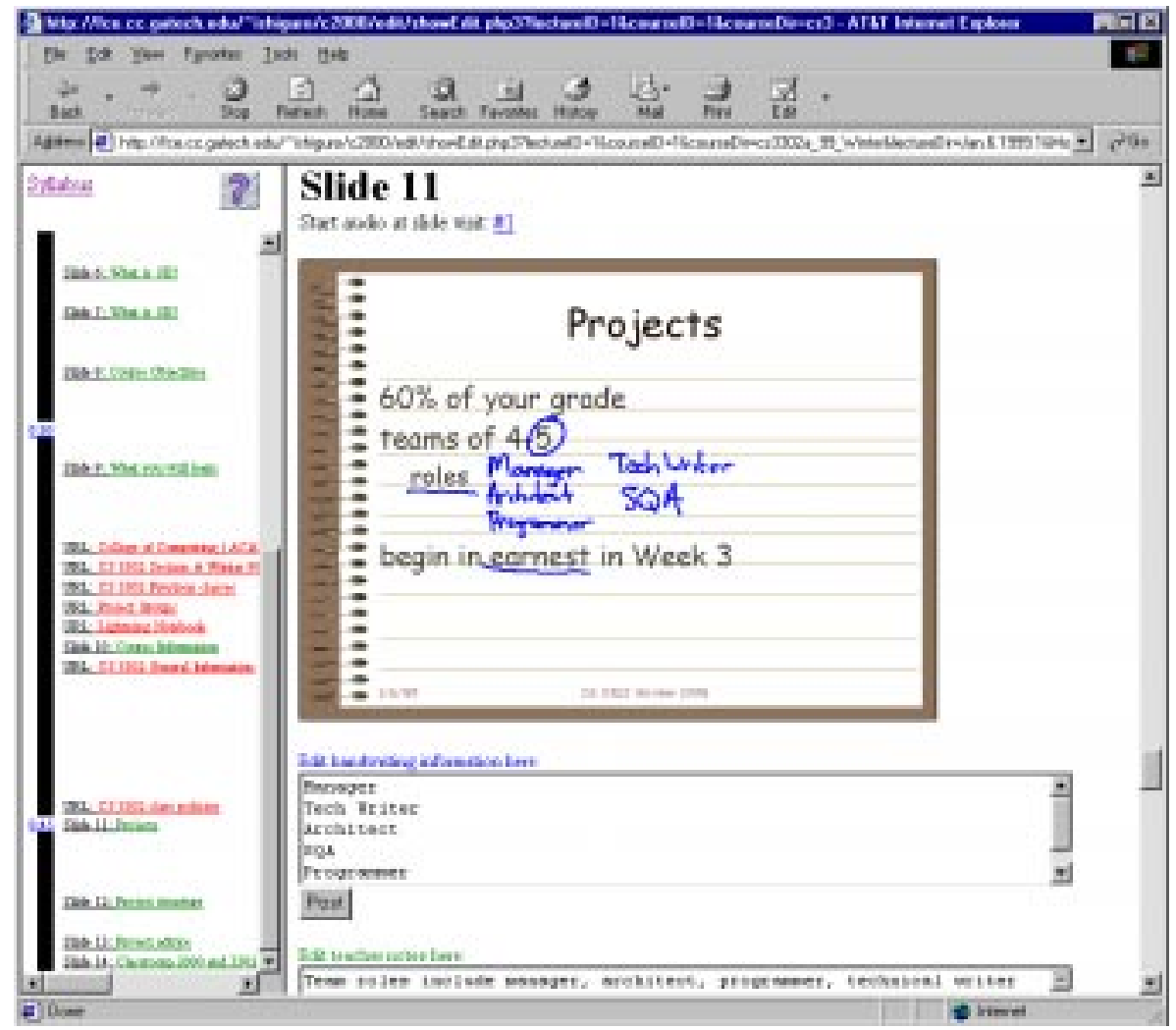

Figure 7: Lecture editing interface 
Any annotation provided by the instructor in the original prepared slides, during the beforelecture phase, is loaded in the database and shown in the presentation interface under the corresponding slide, as illustrated in Figure 8.

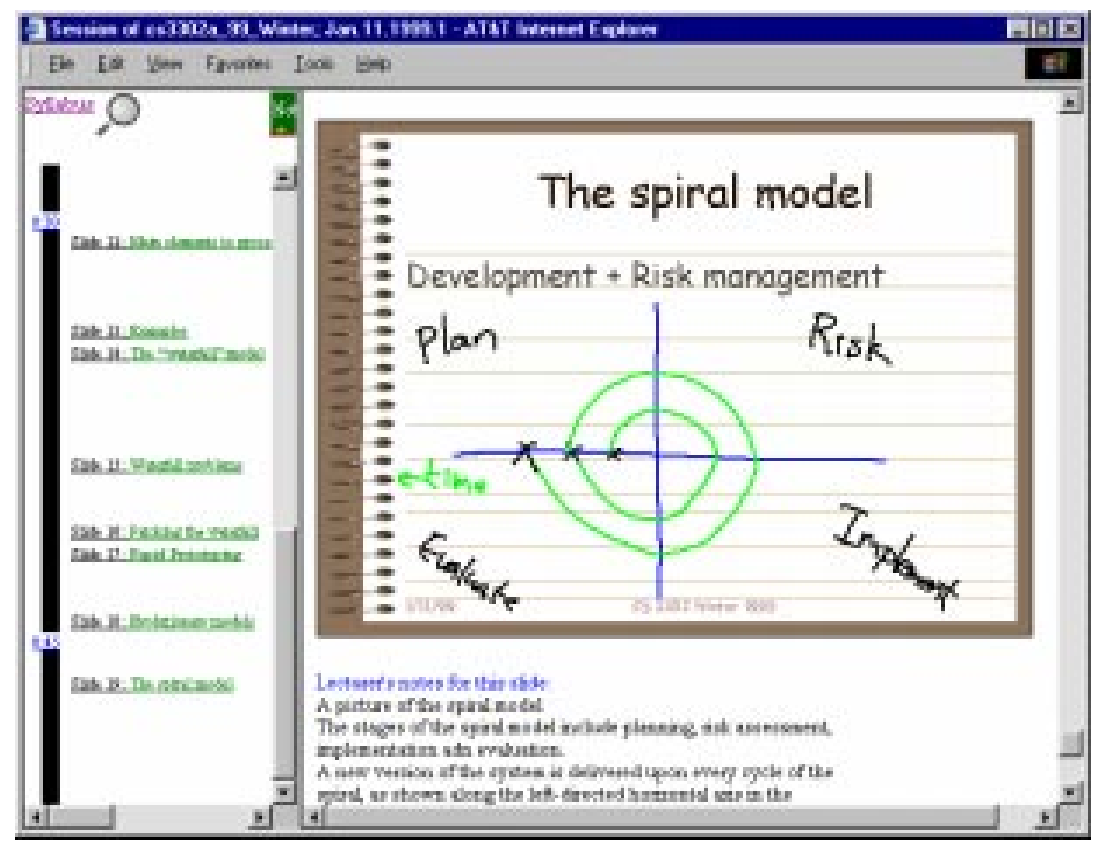

Figure 8: Annotation to a particular slide shown in the presentation interface

\section{Supporting search}

As a course evolves, the quantity of captured information also grows. Using the syllabus organization helps a student locate information from the class, but it is not the only way that is useful. A general search capability over the content of lectures can help a student find a relevant part of a given lecture or see how different lectures are related along a common topic.

We provide a simple search interface, as shown earlier in Figure 4 (directly above the syllabus listing). Given a query phrase, the search engine searches the database for the specific terms in all the information streams available for the course. These streams include the instructor's handwriting, the content of prepared slides, the title and content of Web pages visited and even a 
voice transcript from the lecture. Figure 9 shows screenshots of sample search results. The left screenshot shows a summary of search results over a single course, with thumbnails of various slides from class shown to give some context for search results. These results are divided by lecture and further details can be requested, as shown on the right of Figure 9, and that will indicate the specific details of matches to that particular lecture.
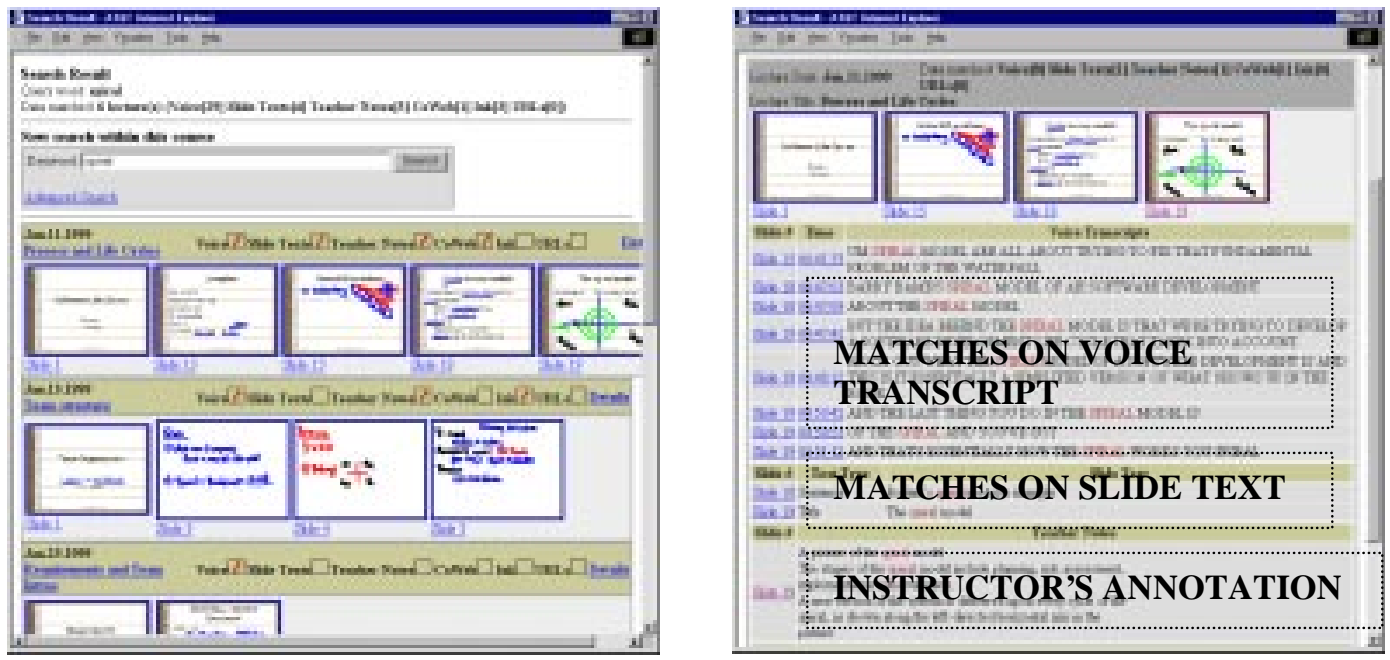

Figure 9: (left) List of lectures and corresponding (thumbnail version of the) slides. (right) Search results classify which type of data matched the query (in this case: voice transcript, text extracted from prepared slide of annotations added by the instructor in the editing interface).

A more elaborated query can be specified in an alternative interface provided. The interface on top of Figure 10 allows the specification of data type, list of lectures and whether or not to use case-sensitive search. The bottom portion of the figure presents the result of a query that specified search of handwriting information data only. The search interfaces can be made available in several scopes, such as in the syllabus page of the course and in the presentation interface of each lecture. 


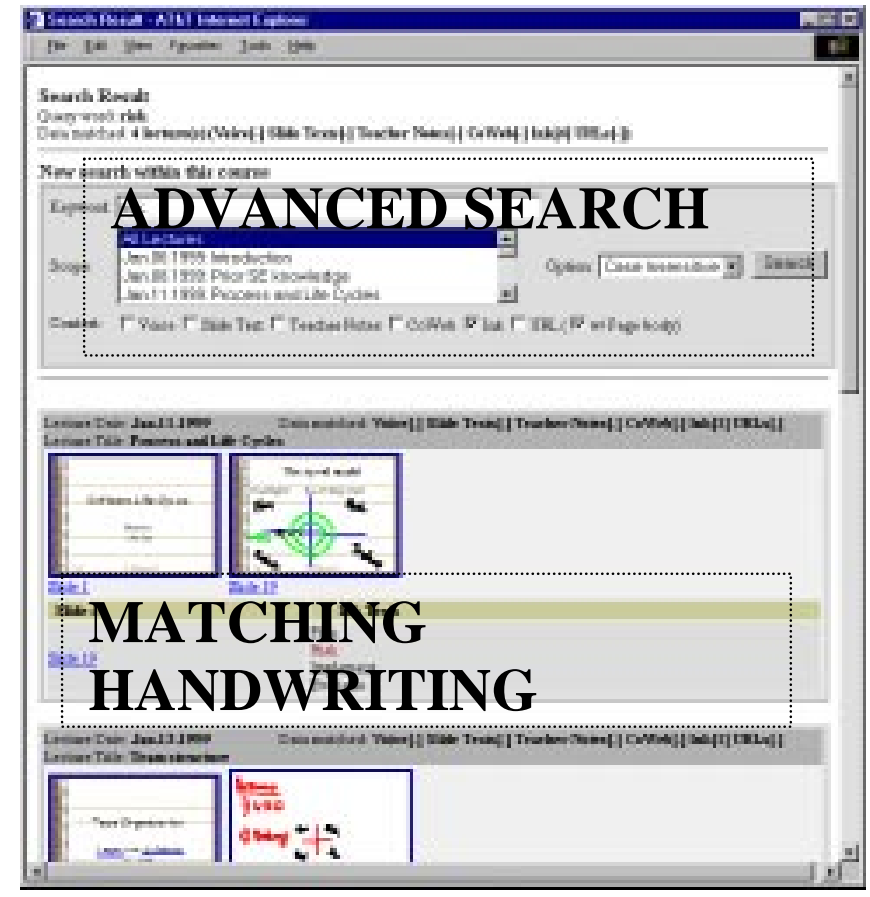

\section{Anchoring Discussions in Lecture: An Approach to Collaboratively Extending Classroom Digital Media}

Many computer-supported collaborative learning (CSCL) environments provide collaboration support in terms of a medium for discussion. Threaded discussion spaces, such as MFKSpeakeasy (Hsi \& Hoadley, 1997), provide a mechanism for asynchronous discussion where the structure of the discussion is reflected in the interface. In chat systems, MUDs, or MOOs (Bruckman, 1994; Bruckman \& Resnick, 1995), the collaborative environment is a medium for synchronous collaboration. However, in classroom-based courses, there is a danger that the discussion forums may be decontextualized from the students' activity.

Several CSCL tools being used in higher education can be used for anchored discussions (e.g., CoNote (Davis \& Huttenlocher, 1995)). Since many higher-education classroom contexts today have syllabi or assignment descriptions available on the Web, these could be used to promote 
anchored collaborations in which the discussion is linked directly to an artifact of interest to students (Guzdial et al., 1997; Guzdial \& Turns, 1999; Hmelo, Guzdial \& Turns, 1998). By anchoring the collaboration to material useful to the students (e.g., a midterm exam review, a problem statement, a report to review), the discussion becomes more relevant to the students' activities. In particular, anchored discussions tend to be more sustained than less-connected discussion spaces, such as newsgroups (Guzdial, 1997). In lower grades where significant resources are available on-line, such as in the Virtual High School (Hsi, 1999), anchored collaboration can be also used.

\section{The CoWeb: a tool for collaborative authoring Web-based material}

One interesting implementation of a CSCL tool is the CoWeb, which allows collaborative authoring of Web-based material (Guzdial, 1999a; Guzdial, 1999b). A CoWeb allows any user to edit any page in its website. In the CoWeb, new pages can be created and linked by anyone, and permission is granted for anyone to edit and create links in already existing pages. This simple infrastructure has supported a wide variety of collaborative activities, from group writing to telementoring. Figure 11 presents a typical front page for a CoWeb site. 


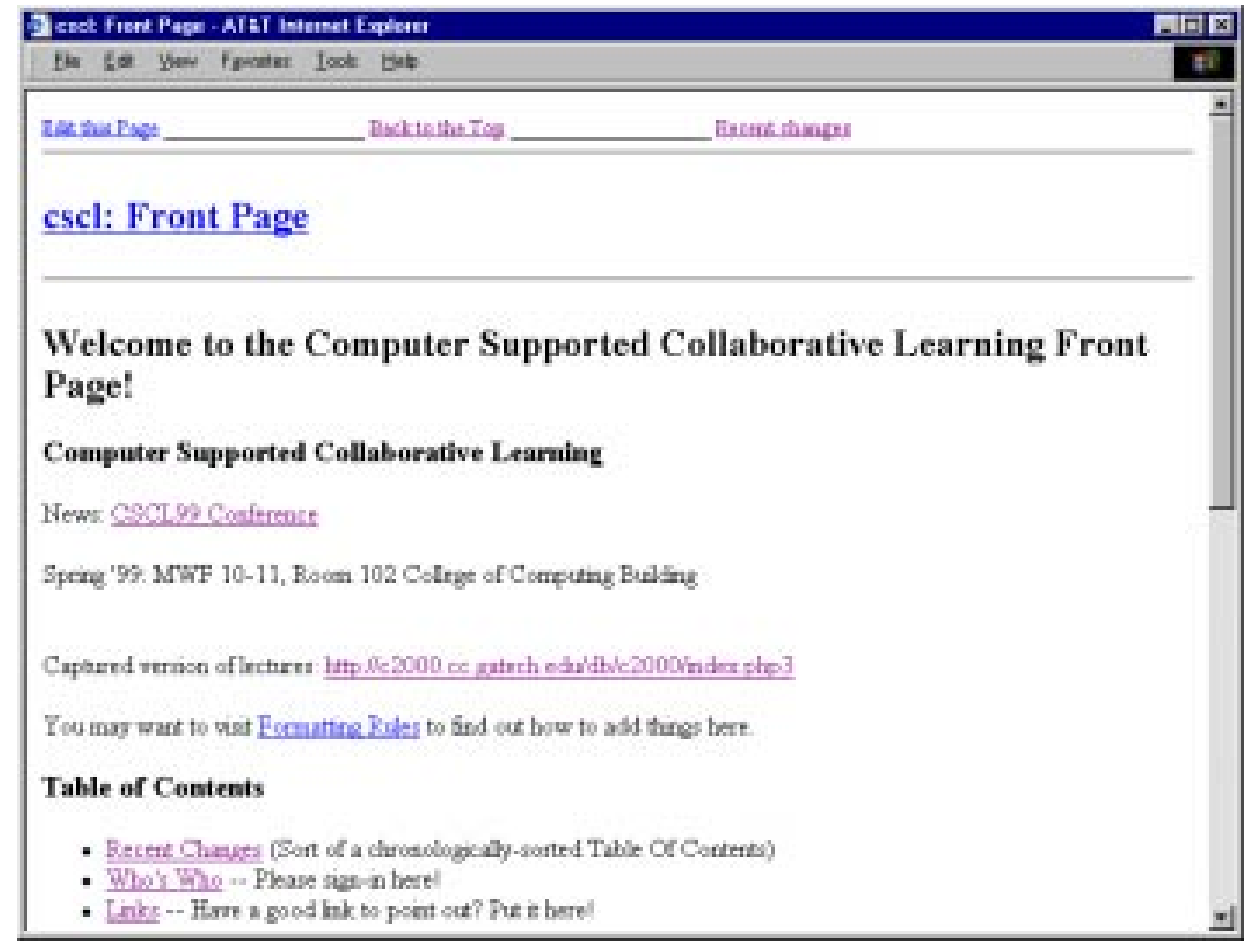

Figure 11: A typical CoWeb Front Page

The interface of a CoWeb page is very simple, and contains a header, a body and footer. The header contains the top line and the name of the page. The topmost line presents a list of links that give access to functions such as Edit this Page and Recent Changes, discussed below. Next, the name of the page is presented; the name itself is associated to the Search for References feature. When the name is selected, a special page listing all pages that make a reference to the current page via a hypertext link is presented. The footer may contain links to services such as a traditional search over all pages. Between the header and the footer is the body of the page, that can be created and edited by any user. 
When the Edit this Page function is activated, the editing interface is presented, as illustrated in Figure 12. The editing interface is a simple Web page that presents the contents of the original page (even if empty) in a form, which can freely modified: any valid HTML contents can be used. The page is saved by submitting the form, and the new contents are immediately presented.

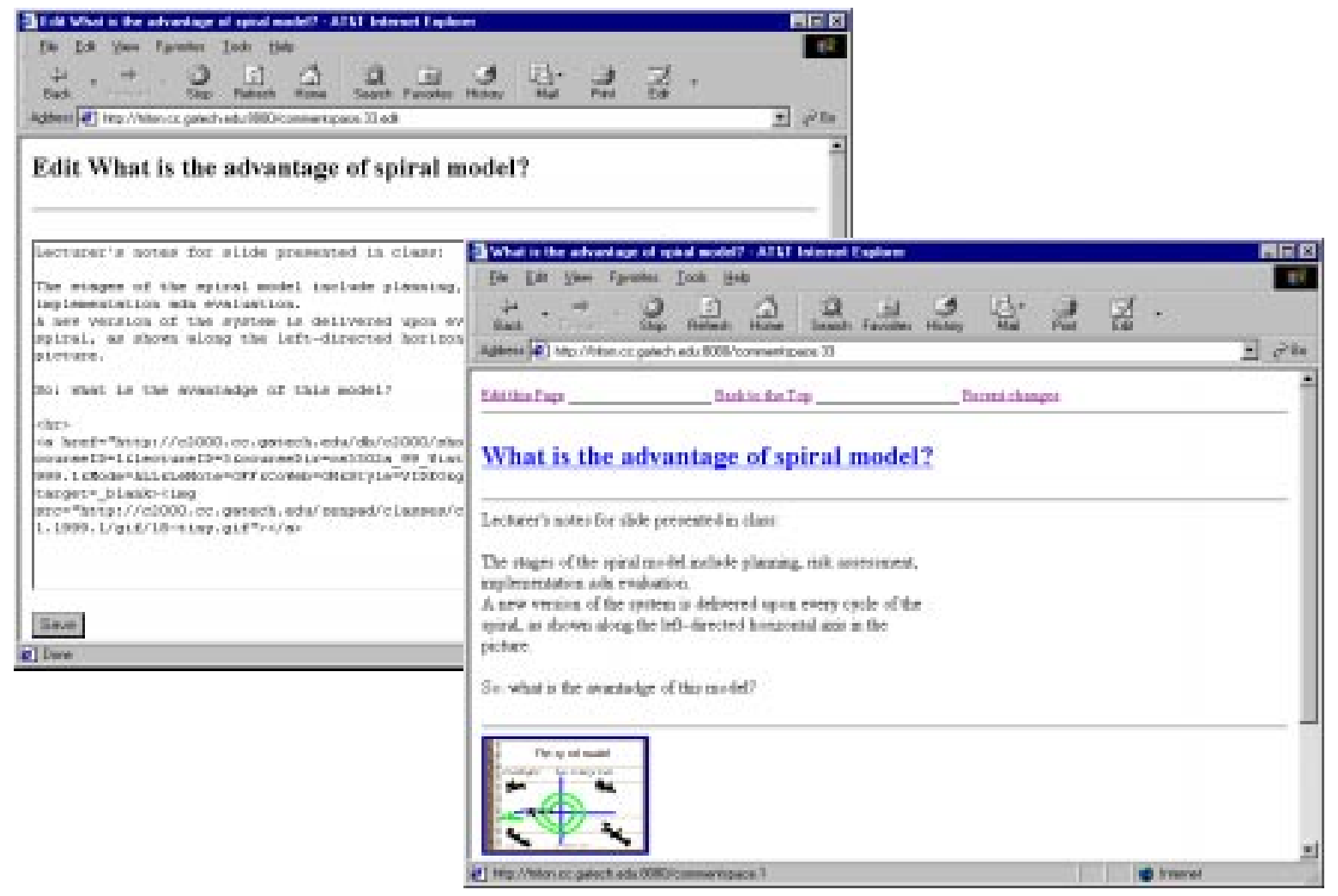

Figure 12: A CoWeb page (foreground) and its editing interface (background).

A feature especially powerful in this context is that the CoWeb is persistent. Pages exist over time. When the Recent Changes feature is activated from any page, a new special page lists 
when each page in the CoWeb has been changed in reverse chronological order, as illustrated in Figure 13, so that new additions or edits can be easily identified.

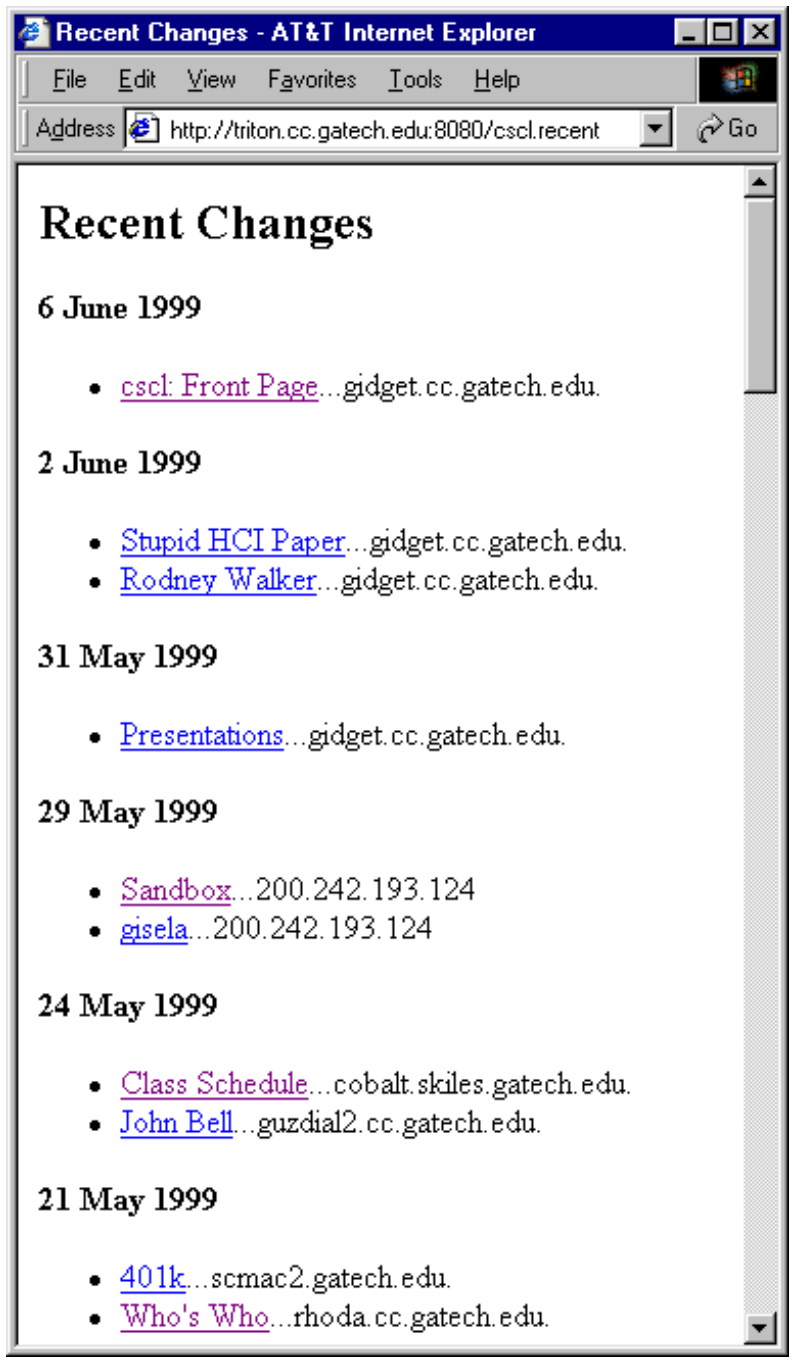

Figure 13: A CoWeb "Recent Changes" page

The CoWeb is a very informal and unstructured Web repository. Any structure can be built by using the capability of creating internal and external links. However, in order to induce its effective use, a few guidelines are usually followed. These include the demand for any user to identify any editions made and the use of appropriate material and structure. 
CoWebs have been used in the same course across multiple instances of the class, or in related courses to create cross-classroom integration and transfer. For this paper, the interest is in how they can be integrated with captured lecture notes to provide anchors between in-class and outside-class activities.

\section{Integrating captured lectures and extended collaborative discussions}

Our vision is for captured classroom activity to serve as one kind of learning media that is available to students outside of the classroom. We want classroom experiences to be segmentable material that can be:

- discussed and extended later;

- persistent over time so that certain experiences (like a particularly nice lecture explanation) can be revisited and even reinterpreted;

- indexed with collaborative discussion spaces; and

- searched for relevant pieces that can be linked to a new discussion or topic, even in new classes and contexts.

To provide such functionality, we integrated the capture system of Classroom 2000 with the CoWeb system. This involved providing ways for the independent information spaces to have links created into the other. A captured lecture needed to have a way to be placed easily into a CoWeb discussion and a CoWeb discussion space needed a way to easily provide a link into a lecture. 
When a student visits the notes from a captured lecture, links to new or ongoing discussion pages in the CoWeb can be created via a simple form interface, as shown in Figure 15. When the CoWeb server receives the link request, it either creates a new discussion page (in the case of a new discussion topic) or appends to the already existing discussion page, adding a thumbnail image of the lecture slide that provides an anchor back to the captured lecture. The resulting CoWeb discussion page is shown in Figure 16. The link established from the captured lecture notes is added, so that a student can jump right to the discussion space, if desired.

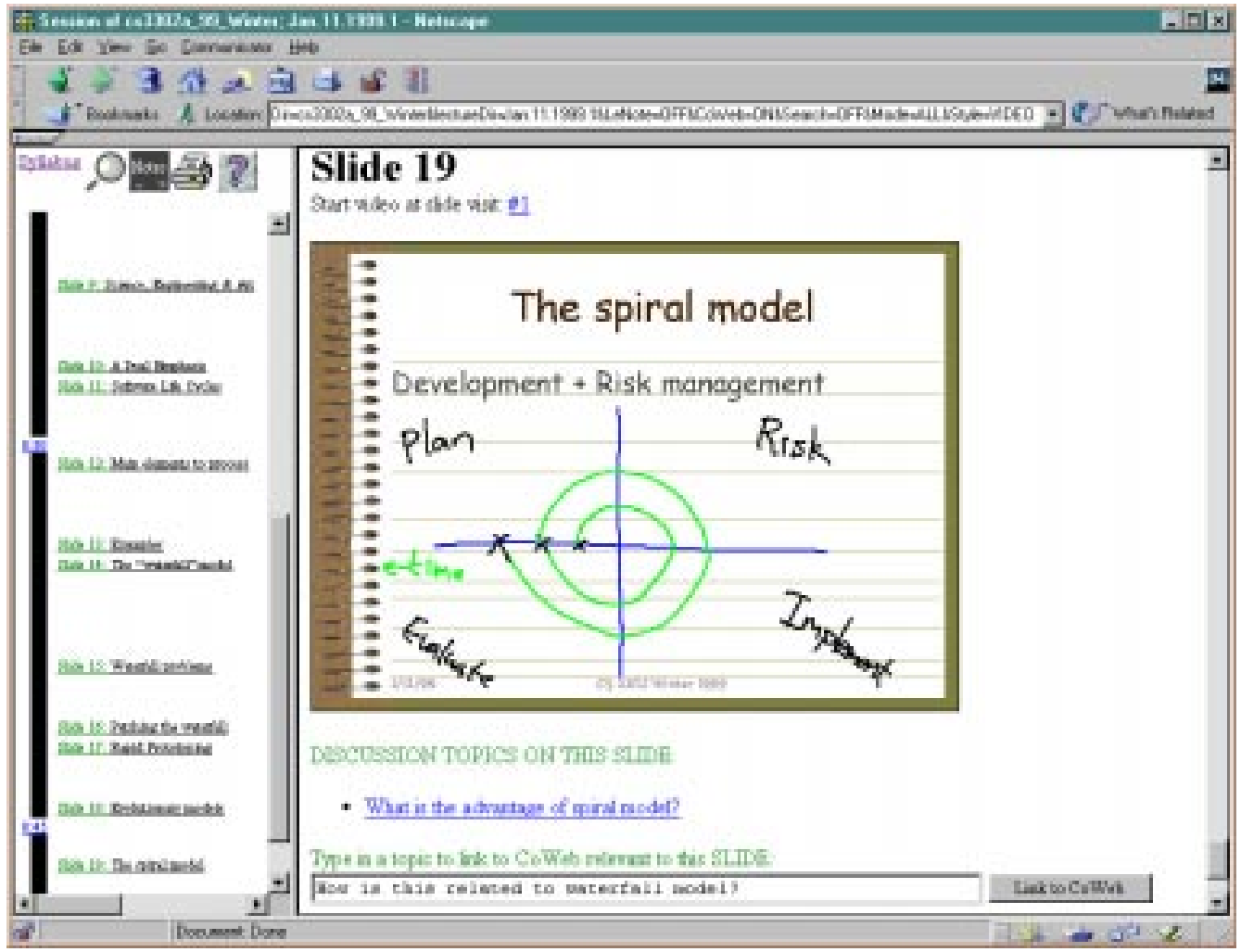

Figure 15: A view of the captured lecture notes. Links to the CoWeb discussion space are shown directly under a slide. A new link can be created after any slide by filling in the simple form beneath that slide. In the example shown here, the student enters "How is this related to the waterfall model?" to create a new discussion page in the CoWeb that will be automatically linked to this point of the captured lecture. 
Viewing a CoWeb entry from the captured lecture notes

When a student is viewing captured lecture notes, all links to the CoWeb discussion space are shown, as in Figure 15. If the student selects a link to a discussion page, that CoWeb page is shown in a new browser. The CoWeb page will include a thumbnail image of the slide that links back to the captured lecture, as shown in Figure 16.

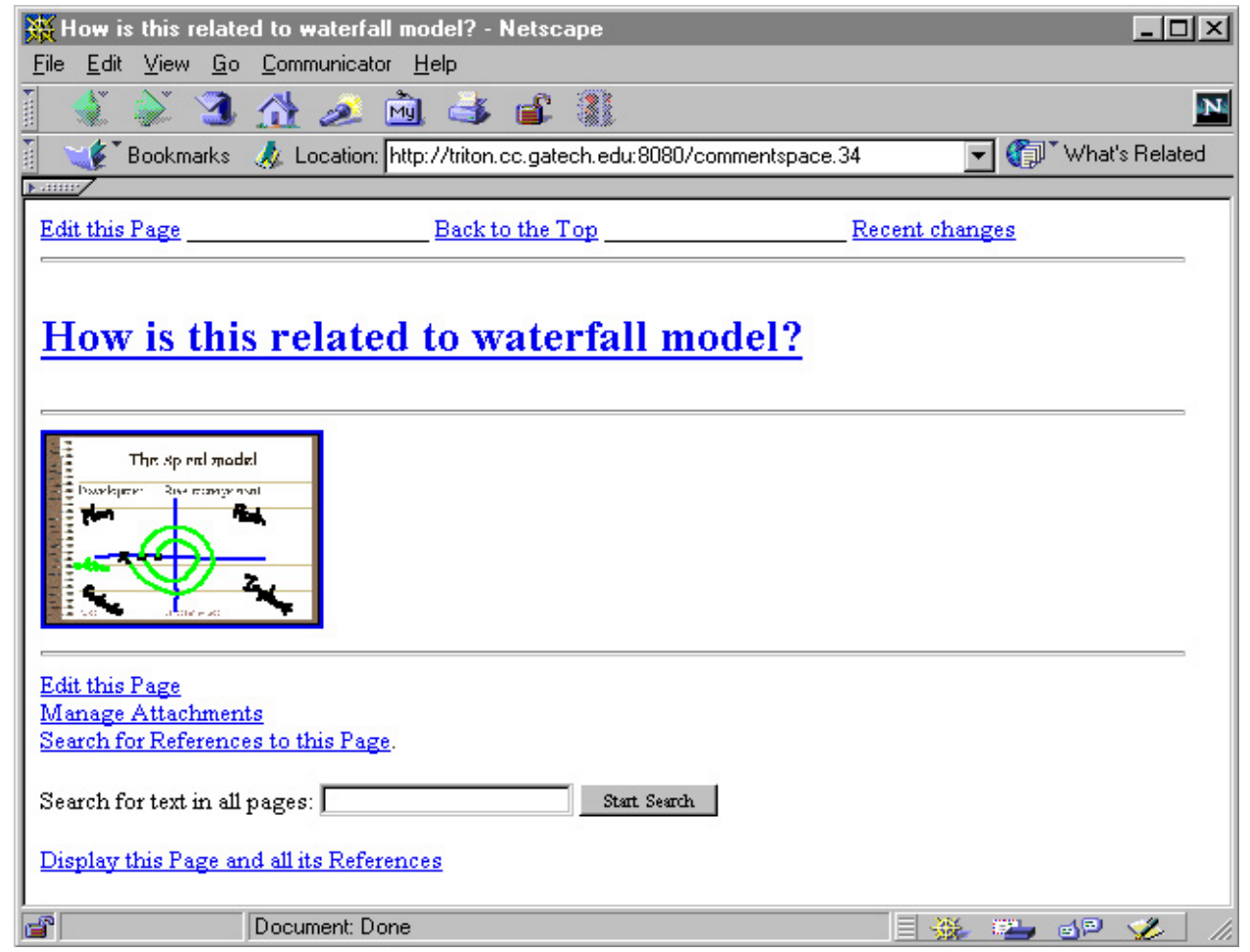

Figure 16: A view of a CoWeb page. This particular page corresponds to the entry created from the captured lecture notes shown in Figure 15. The thumbnail image is a link back to the captured lecture and was automatically created when the link request was made. 


\section{EXPERIENCE IN A LIVING ENVIRONMENT}

Throughout the Classroom 2000 project, we have sought to validate the utility of automated capture in the educational domain through extensive and authentic use. To date, we have captured most lectures in over 100 undergraduate and graduate courses in the College of Computing at Georgia Tech. Initial evaluation results from this extensive experience have been reported elsewhere (Abowd, 1999) and deeper evaluation will be reported in the future. To gain experience with the integration of lecture capture with the CoWeb discussion space, we experimented with a graduate seminar course in the Spring of 1999 . This computer science course was taught by one of the authors (Abowd) and another co-instructor, and had 31 students, both graduate and senior undergraduate. In total, there were 18 lectures over a 10-week period, consisting of 27 hours of lecture (with audio and video), covering 307 slides of information and 486 Web pages visited. Seven of the lectures had a prepared lecture presentation, and the remaining 11 used a blank whiteboard. The course consisted of a mix of traditional lecture and discussions based on a large number of outside readings, 69 in total, that were listed off a separate Web page from the course Home Page and were mostly available on-line for reading. After class, one instructor manually transcribed the handwriting on the electronic whiteboard (205 of 317 slides), added titles to slides that did not have one already (101 of 317 slides) and provided additional commentary on some slides (27 of 317 ).

Use of the CoWeb was required in the class, so a lot of activity was created in that discussion space, totalling 303 independent pages created by students and instructors. For each reading assigned in class, one or more students were assigned responsibility for preparing a summary of the paper and posting it to the CoWeb prior to the lecture. Students and instructors were free to 
read and comment upon the reading summary. The papers were usually discussed in class and students were then responsible for updating their summary based on lecture discussion. Student groups were responsible for two external projects in the class, and the project reports were to be posted to the CoWeb as well. Occasionally, projects were presented in class and all were commented upon by the instructors. Students were encouraged to comment on projects of other groups, but very little commentary was provided via the CoWeb. As a result of this extensive use of the CoWeb as part of this course, the vast majority (over 90\%) of the CoWeb pages were initially generated by students.

Each CoWeb page was visited and average of 62 times and edited and average of 11 times. By the end of the quarter, the average CoWeb page had been in the discussion space for 29 days. Visits to the CoWeb experienced a steady growth, with an average of 2173 hits per week, which indicates fairly intense activity throughout the term. The most visited pages in the CoWeb were those corresponding to landmarks in terms of deliverables or assignments in the course. Eight out of the ten most visited pages were those that indexed into material such as reading summaries or project summaries. This certainly indicates the appropriateness of such landmarks and indexing as resources for aiding the users to navigate over the underlying hypertext structure of the material.

Since much of the CoWeb material was discussed in class, there was a natural desire to link what was produced in the CoWeb with the lecture at various points. It was also possible when writing a reading summary or doing an external project, that topics would be discussed that were already brought up in previous lectures. Therefore, we saw a potential use for two-way links between the repository of captured lectures and the CoWeb discussion space. 66 links were made during the course between captured lectures and the CoWeb space, for an average of 3.6 links per 


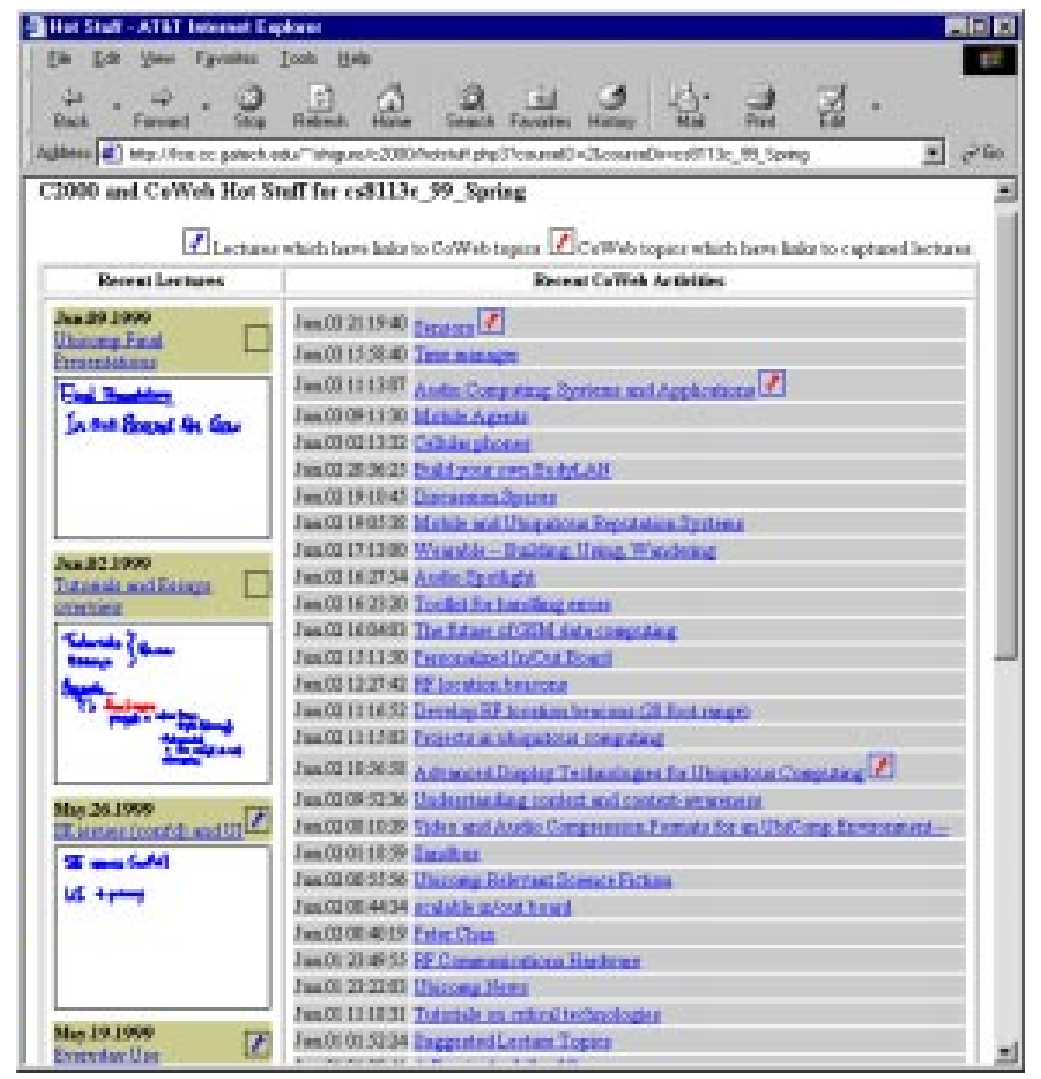

Figure 17: The HotStuff page shows most recent changes in combined repository.

lecture. That is not as high a value as had been expected, but not surprising for such a novelty.

Indeed, we suspected that the majority of these cross-repository links would be generated by the instructor, but found that only 11 of the 66 links were instructor-generated.

Students indicated that they found the Recent Changes feature of the CoWeb useful for navigating that discussion space. This feature was accessed a total of 1446 times throughout the term, which is a very strong indicator of its value. It provided a simple way to find out what was new information in the loosely organized space. Although the environment we provided students integrated the captured lectures with the discussion space through manual linking, we did not provide an interface to let the student understand "recent changes" in the integrated space. In response, we designed a separate and dynamically-generated Web page, called HotStuff that 
produced a listing of newly captured lectures as well as a summary of CoWeb recent changes. This interface, shown in Figure 17, also indicates when a lecture is linked to CoWeb space and vice versa. The captured lectures are listed in the leftmost column, displaying the first slide created for the four most recently captured lectures. For each lecture, additional information includes the title and date of the lecture, and an icon indicates when that lecture contains a link to pages in the CoWeb. The column in the right hand side presents the list of CoWeb pages edited in the same period, with the date and time of edition. An icon also indicates whether that CoWeb page has a link to the captured notes for a lecture.

Our preliminary experience shows that there are very interesting technical questions to be addressed in providing effective interfaces to this dynamic educational repository. Before continuing this research, however, we must answer the question of whether this is a useful educational endeavor. For that answer, we surveyed the students to find their reactions to the integration between captured lectures and the CoWeb discussion space. 21 of the 31 students responded to our survey about halfway through the term. In general, the students made more use of the CoWeb than the captured lecture notes. $71.4 \%$ of the students visited the captured lecture notes at least once a week and $95.2 \%$ visited the CoWeb discussion space at least once a week. In most Classroom 2000 supported courses, we have noticed quite significant access to the captured lectures, especially around exam times. The course that was the subject of this experiment did not have any formal exams, so we are not surprised by the lower apparent use of the captured lecture notes (though it was certainly not negligible).

Considering the captured notes and the CoWeb pages separately, the students reported that they believe they attained a better understanding of the material in class with the use of the CoWeb pages (85.7\% agree, $9.5 \%$ neutral, $4.8 \%$ disagree) than through the captured lecture notes $(57.1 \%$ 
agree, $38.1 \%$ neutral, $4.8 \%$ disagree). This is not surprising, given the structure of the course and there being no traditional exam in the course. However, considering the integrated environment, it is interesting that over half of the group (66.7\%) perceived that they had a better understanding of the material in class through coordinated use of both captured notes and the CoWeb discussion space (28.3\% neutral, $4.9 \%$ disagree). Students felt it was useful to be able to access the CoWeb pages from the $\mathrm{C} 2000$ captured notes (57.1\% agree, 42.9 neutral), and, conversely, to access the captured lectures from the CoWeb pages $(52.4 \%$ agree, $42.9 \%$ neutral, $4.8 \%$ disagree). This indicates that, for a course with such a format, the integration of the access to the material, as provided, gives further supported for the learning tasks from the user's perspective. This result is also a positive indication that the service provided helped the students to deal with the active growth and intrinsic referencing properties of the material.

\section{Conclusion And Future Work}

In this paper, we have examined some of the issues involved in providing effective interfaces to a dynamic repository of educational material. We can view educational material generated by a single course as an ever-growing repository of information that instructors and students contribute to through activities that occur before, during and after the traditional lecture. The lecture itself can be viewed as a multimedia authoring session in order to create browsable, searchable, and extensible Web-accessible media that reflects this critical component of the educational experience. In addition, anchored collaborative discussions can link between the live lecture and other pieces of educational material.

We have demonstrated the possibility of such a repository that links in-class and outside-class activities and we have gained experience using this system for an entire course. Our preliminary experience indicates that this integration of in-class and outside-class material is useful and 
worthy of more serious evaluation. Our study was limited to evaluation within the context of a single instance of a course. We expect that the real advantages of a large-scale educational repository arise over the long-run. When a student's entire educational experience is preserved in a way that facilitates search and annotation (through services similar to a CoWeb), even greater

benefits will accrue. These benefits, in fact, are not limited to the student. We already have plenty of anecdotal evidence of teachers using the captured lecture repository to help them prepare lectures based on their previous versions of a course or based on lectures given by other, trusted faculty. To be able to support such a long-term and personalized educational repository, there are several research questions that we need to address, including a better integration between in-class and out-of-class repositories. The experiment described in this paper detailed the integration of two established repositories, and we learned a lot that will inform the redesign of both of those repositories to make them more amenable to extension and integration with other educational repositories. A major goal for the future is to provide greater capabilities to reuse captured material and associated discussion spaces in future educational experiences.

\section{ACKNOWLEDGEMENTS}

This work has been sponsored in part by grants from the National Science Foundation (IRI9703384, EIA-9806822 and CISE-9818305) and FAPESP-Brazil (PD-98/05984-7). The authors would like to acknowledge generous equipment grants from Sun Microsystems and HewlettPackard that have supported the Classroom 2000 effort. Dr. Pimentel and Mr. Ishiguro were both visitors at Georgia Tech where this research was completed and we thank their sponsoring institutions for support. Finally, the authors would like to thank various researchers in the Future Computing Environments Group at Georgia Tech for their lasting intellectual contributions to the 
Classroom 2000/eClass project, specifically Christopher Atkeson, Jason Brotherton and Khai Truong.

\section{REFERENCES}

Abowd, G.D. Classroom 2000: An experiment with the instrumentation of a living educational environment. IBM Systems Journal. 38(4):508-530 1999.

Abowd, G.D., Atkeson, C.G., Brotherton, J.A., Enqvist, T., Gully, P.A., \& Lemon, J. Investigating the capture, integration and access problem of ubiquitous computing in an educational setting. Proceedings of CHI'98, ACM, New York, pp. 440-447.

Abowd, G.D., Atkeson, C.G., Feinstein, A., Hmelo, C., Kooper, R., Long, S. Sawhney, N. \& Tani, M. Teaching and Learning as Multimedia Authoring: The Classroom 2000 Project. Proceedings of the ACM Multimedia'96, pp. 187-198, November 1996.

Brotherton, J.A, Bhalodia, J. \& Abowd, G.D. Automated Capture, Integration, and Visualization of Multiple Media Streams. In the Proceedings of IEEE Multimedia '98, pp. 54-63, July, 1998.

Bruckman, A. (1994). Programming for Fun: MUDs as a Context for Collaborative Learning, Proceedings of the National Educational Computing Conference (NECC'94). Eugene, OR: International Society for Technology in Education (ISTE).

Bruckman, A., \& Resnick, M. (1995). The MediaMOO Project: Constructionism and Professional Community. Convergence, 1(1), 94-109.

Davis, J. R., \& Huttenlocher, D. P. (1995). Shared Annotation for Cooperative Learning. In J. L. Schnase \& E. L. Cunnius (Eds.), CSCL'95 Proceedings (pp. 84-88). Bloomington, IN: Lawrence Erlbaum and Associates. 
Guzdial, M. (1997). Information ecology of collaborations in educational settings: Influence of tool. In R. Hall, N. Miyake, \& N. Enyedy (Eds.), Proceedings of Computer-Supported Collaborative Learning'97 (pp. 83-90). Toronto, Ontario, Canada.

Guzdial, M. (1999a). Supporting Learners as Users. The Journal of Computer Documentation, 23(2), 3-13.

Guzdial, M. (1999b). Teacher and Student Authoring on the Web for Shifting Agency: Presented at the Annual Meeting of the American Educational Research Association as part of the session How can CSCL (Computer Supported Collaborative Learning) change classroom culture and patterns of interaction among participants?

Guzdial, M., Hmelo, C., Hübscher, R., Nagel, K., Newstetter, W., Puntembakar, S., Shabo, A., Turns, J., \& Kolodner, J. L. (1997). Integrating and Guiding Collaboration: Lessons learned in computer-supported collaboration learning research at Georgia Tech. In R. Hall, N. Miyake, \& N. Enyedy (Eds.), Proceedings of Computer-Supported Collaborative Learning'97 (pp. 91-100). Toronto, Ontario, CANADA.

Guzdial, M., \& Turns, J. (1999). Supporting sustained discussion in computer-supported collaborative learning: The role of anchored collaboration. Journal of the Learning Sciences(Submitted).

Hmelo, C. E., Guzdial, M., \& Turns, J. (1998). Computer-support for collaborative learning: Learning to Support Student Engagement. Journal of Interactive Learning Research, 9(2):107130. 
Hsi, S. (1999). Fostering effective instruction in a virtual high school: A netcourse for teachers: Paper presented at the 1999 Annual Meeting of the American Educational Research Association, in session 27.01 The Virtual High School in Action.

Hsi, S., \& Hoadley, C. M. (1997). Productive discussion in science: Gender equity through electronic discourse. Journal of Science Education and Technology, 6(1):23-36.

Murray W. Goldberg and Sasan Salari (1997). An Update on WebCT (World-Wide-Web Course Tools) - a Tool for the Creation of Sophisticated Web-Based Learning Environments, Proceedings of NAUWeb '97 - Current Practices in Web-Based Course Development, June 12 15, 1997, Flagstaff, Arizona. http://www.webct.com/webct/papers/nauweb/full-paper.html

Pimentel M.G.C., Fortes, R.P.M, Santos Jr. J.B (1998). Modeling, authoring and presenting structured documents in the WWW, Journal of Universal Computer Science (JUCS), Spring Verlag, 4(11): 825-838.

Truong, K.N. \& Abowd, G.D. (1999). StuPad: Integrating Student Notes with Class Lectures. Proceedings of CHI'99, ACM, Pittsburgh, USA. May 1999, pp. 28-209. 